Article

\title{
Lipase-Catalysed In Situ Transesterification of Waste Rapeseed Oil to Produce Diesel-Biodiesel Blends
}

\author{
Egle Sendzikiene *(D), Migle Santaraite and Violeta Makareviciene \\ Faculty of Forest Sciences and Ecology, Agriculture Academy, Vytautas Magnus University, K. Donelaicio str. 58, \\ LT-44248 Kaunas, Lithuania; migle.santaraite@vdu.lt (M.S.); violeta.makareviciene@vdu.lt (V.M.) \\ * Correspondence: egle.sendzikiene@vdu.lt
}

Received: 17 July 2020; Accepted: 4 September 2020; Published: 8 September 2020

\begin{abstract}
Rapeseed oil of high acidity, an agricultural industry by-product unsuitable for food, was used as an inexpensive raw material for the production of biodiesel fuel. The use of rapeseed oil that is unsuitable for food and lipase as a catalyst makes the biodiesel production process environmentally friendly. Simultaneous oil extraction and in situ transesterification using diesel as an extraction solvent was investigated to obtain a diesel-biodiesel blend. The diesel and rapeseed oil blend ratio was 9:1 $(w / w)$. The enzymatic production of biodiesel from rapeseed oil with high acidity and methanol using eleven different lipases as biocatalysts was studied. The most effective biocatalyst, lipase-Lipozyme TL IM (Thermomyces lanuginosus), which is suitable for in situ transesterification-was selected, and the conversion of rapeseed oil into fatty acid methyl ester was evaluated. The influence of the amount of methanol and lipase, the reaction temperature and the reaction time were investigated to achieve the highest degree of transesterification. The optimal reaction conditions, when the methanol to oil molar ratio was 5:1, were found to be a reaction time of $5 \mathrm{~h}$, a reaction temperature of $25{ }^{\circ} \mathrm{C}$ and a lipase (Lipozyme TL IM) concentration of 5\% (based on oil weight). Under these optimal conditions, $99.90 \%(w / w)$ of the rapeseed oil was extracted from the seed and transesterified. The degree of transesterification obtained was $98.76 \%(w / w)$. Additionally, the glyceride content in the biodiesel fuel was investigated and met the requirements perfectly.
\end{abstract}

Keywords: biodiesel; diesel fuel; in-situ transesterification; lipase

\section{Introduction}

Biodiesel fuel, produced from renewable raw materials such as animal fats or vegetable oils, is a better choice then diesel fuel. Various methods and technologies that can be used to produce biodiesel using the transesterification process have been explored [1]. A good alternative to the synthesis or production of biodiesel is the in situ transesterification process, which involves fewer steps because "in situ" in the context of transesterification refers to the direct use of the lipid-containing raw materials without lipid extraction before transesterification. Before starting the in situ transesterification process, it is important to know how much oil is contained inside the raw material being used for the in situ transesterification because the amount of oil determines the yield of the ester [1].

Beginning with the first published research on the production of biodiesel from oil-containing raw materials, more than 350 oil-containing materials were explored as potential raw materials for biodiesel production [2]. These raw materials can be classified into five main classes: Oilseeds, agricultural waste, microbial biomass, microalgae, and biological waste [1]. It is important to widely investigate oil-containing raw materials that have no competition with the food industry and are suitable for the in situ transesterification process. However, among the hundreds of investigated raw materials, only a small fraction has been investigated for in situ transesterification. The following non-edible raw materials have already been investigated: Jatropha seeds [3], Karanja seeds [4], Castor seeds [5], Cynara 
cardunculus L. seeds [6], cottonseeds [7], spent coffee grounds [8,9], municipal sludge [10] and some strains of microalgae used for feedstock [11,12]. According to the requirements of Directive (European Union) 2015/1513, the countries of the European Union must increase the use of renewable energy sources in the transport sector up to $10 \%$ by 2020. First generation biofuels in the transport sector's renewable energy sources should be $\leq 7 \%$, while second generation biofuels (excluding those made from used cooking oil) should be met of $2.8 \%$ of the transport sector's renewable energy sources. In this study, oil-containing rapeseed waste was used as the raw material. These seeds are an agricultural industry by-product and unsuitable for use as food; thus, the production of biodiesel from these seeds does not compete with the food industry.

The effectiveness of the in situ transesterification process in the production of biodiesel mainly depends on the choice of raw material, the type and amount of alcohol, the type and amount of catalyst, the operating temperature and the reaction time. From high acidity oils, it is possible to produce high quality methyl, ethyl or butyl esters during the in situ transesterification process using short chain alcohols, such as ethanol and butanol, but the most common and effective alcohol used for in situ transesterification with many different feedstocks is methanol $[1,13,14]$. Methanol, as one of the most widely used alkyl donors, is particularly preferred because of its physical and chemical advantages, such as its short chain, to provide better conversions [15].

There are many different catalysts suitable for the in situ transesterification process, such as acidic catalysts, alkaline catalysts, and enzymatic biocatalysts [16-18]. Alkaline catalysts need moderate reaction conditions and a lower corrosion risk than do acidic catalysts because they are susceptible to higher amounts of free fatty acids or water in reaction media. By comparing the in situ transesterification process with the conventional process, it is known that the former requires a larger amount of alcohol and catalyst [19-22]. Nevertheless, alkaline catalysis has some disadvantages of the biodiesel production process. Because of the formation of soaps that act as emulsifiers, it is difficult to purify the resulting product by separating the glycerol and catalyst. For this reason, it is impossible to use a low-quality oil with a high content of free fatty acids and to regenerate and reuse the catalyst, which is uneconomical [23]. A biotechnological production method using biocatalysts-lipases-can easily eliminate these disadvantages, especially when using very acidic oils. The current state of the lipase-catalysed production of biodiesel through the in situ transesterification of plant oils from various feedstocks and alcohols was reviewed. The lipase-catalysed in situ transesterification process using Jatropha seeds (Jatropha curcas L.), fermentation preparation-Lipozyme TL IM as a biocatalyst, methanol and n-hexane as a co-solvent were studied, and the highest yield $(90.6 \%(w / w))$ of biodiesel was achieved under these optimum conditions: a Lipozyme TL IM concentration of 15\% (based on oil weight), an methanol to oil molar ratio of 6:1, an n-hexane to seed ratio of $3.5: 1 \mathrm{mg} / \mathrm{l}$, a temperature of reaction of $45^{\circ} \mathrm{C}$ and a time of reaction of $12 \mathrm{~h}$ [24]. Fermentation preparation Lipozyme TL IM is a lipase originating from Thermomyces lanuginosus and that is immobilized on a non-compressible silica gel carrier. This lipase is a highly effective catalyst for transesterification process and can transform fatty acids preferentially. In other scientific publications the lipase-catalysed in situ transesterification process using Pistacia (Pistacia chinensis B.) and Jatropha (Jatropha curcas L.) seeds and the alcohols methanol and ethanol, and the highest yields of jatropha methyl ester and jatropha ethyl ester, pistacia methyl ester and pistacia ethyl ester of $95.9 \%, 94.5 \%, 89.6 \%$ and $90.7 \%$ were achieved according to the selected optimal conditions: A Novozyme 435 concentration of $10 \%$ (based on oil weight), a temperature of reaction of $50{ }^{\circ} \mathrm{C}$ and a time reaction of 24 to $36 \mathrm{~h}$ [25]. Other scientists have investigated, self-catalysed (without an additional catalyst) in situ transesterification processes where the germinated seeds were milled to flour consistency (up to particles size smaller than $1 \mathrm{~mm}$ ). Castor seed powder used as the substrate and as the catalyst. In these studies, dimethyl carbonate used to extract the oil and as the acyl acceptor to produce biodiesel. The yield of biodiesel (87.41\%) was obtained under the following optimum conditions: The dimethyl carbonate to germinated seed ratio was $12.5 \mathrm{~mL} / \mathrm{g}$, the germination time of castor seed was $72 \mathrm{~h}$, and the reaction temperature was $35^{\circ} \mathrm{C}[26]$. 
In this study, waste rapeseed (unsuitable for food) with high oil acidity was used as the raw material for the lipase-catalysed in situ transesterification process for biodiesel production instead of using high quality rapeseeds. This offers the possibility to transform oil-containing biodegradable waste in to a sustainable and renewable energy source. Considering that biodiesel, as fuel, is generally used in blends with diesel and that a solvent increases transesterification efficiency as per study findings, we chose diesel as a solvent. It is known that diesel and biodiesel blends are the most common used as fuel for diesel engines. Taking into account that diesel can be used as an extraction solvent, it is possible to eliminate the mixing of pure diesel with biodiesel stage using biodiesel and diesel mixture for in situ process directly [27]. Other scientists also used diesel, as solvent for oil extraction from Ankistrodesmus fusiformis microalgae biomass. At this research, Lipozyme TL IM was used as catalyst and alcohol-ethanol for in situ transesterification process with ultrasound treatment. To obtain $97.69 \%$ of the transesterification yield, reaction conditions were as follows: Temperature of reaction $-42{ }^{\circ} \mathrm{C}$, molar ratio of ethanol to oil- $8: 1,9.6 \%$ of catalyst and time of reaction-12 h [28]. Same catalyst, Lipozyme TL IM and ethanol were used by other scientists, for production of biodiesel from microalgae oil by its transesterification in the mixture with diesel fuel. The transesterification yield of the product was reached of $98 \%$ under the above conditions: $13.26 \%$ of catalyst Lipozyme LT IM (from the oil content), molar ratio of ethanol to oil of $4.54: 1$, a temperature of reaction of $30^{\circ} \mathrm{C}$ and time of reaction of $13 \mathrm{~h}$ [29].

The aim of our investigation was not only to extract the highest amount of oil from rapeseed feedstock but also to maximise transesterification effectiveness using methanol as acyl receptor and lipase as catalyst. The reaction product was diesel-biodiesel blend, which can be directly used in diesel vehicles as fuel. The biodiesel content of $10 \%$ in the blend with diesel fuel was selected due taking into account the requirements of biodiesel consumption set in national and European Union normative documents.

The purpose of this investigation was to analyse how operating parameters, such as the concentration of lipase, the temperature and the time of reaction, influence the degree of transesterification and glyceride content (monoglycerides, diglycerides, and triglycerides) in a reaction product—-diesel and biodiesel blend.

\section{Materials and Methods}

Rapeseed used for the research was grown, collected and imported from the Educational Experimental Station of Vytautas Magnus University Agriculture Academy (Kaunas, Lithuania). Only low-quality rapeseed with higher acidity of oil were used for this research. Diesel (Artic climate zone, class 1, met the requirements of the standard EN 590 and test methods was purchased from a local (Kaunas, Lithuania) market). Methanol (analytically pure) was purchased from Sigma-Aldrich Chemie Gmbh (Munich, Germany). Eleven immobilized and not immobilized fermentation used as biocatalysts, were kindly donated form the global biotechnology company Novozymes A/S, Copenhagen, Denmark.

\subsection{Seed Quality Analysis}

To determine the quality of the seeds, five main criteria were analysed and evaluated according to the standards: The rapeseed oil content (the standard ISO 659 [30]), the fatty acid composition of methyl esters of rapeseed oil (the standards EN ISO 5509 [31] and EN ISO 5508 [32]), the acid value of the extracted rapeseed oil (the standard ISO 660 [33]) and the rapeseeds moisture content (the standard ISO 665 [34]).

\subsection{Selection of Lipase for In Situ Transesterification}

Eleven different types of fermentation preparations (lipases) suitable as biocatalysts for the in situ transesterification process to produce biodiesel were selected. Some of these fermentation preparations tested in this study were immobilized: Lipozyme RM IM (Lipase from Rhizomucor miehei, $>30 \mathrm{U} / \mathrm{g}$ ), Lipozyme TL IM (Lipase from Thermomyces lanuginosus, $\geq 3000$ U/g), Novozyme 435 (Lipase from 
Candida antarctica, $\geq 5000 \mathrm{U} / \mathrm{g}$ and Lipozyme 435 (Lipase from Candida antarctica, $600 \mathrm{U} / \mathrm{g}$ ), other lipases were not immobilized: Lipolase $100 \mathrm{~L}$ (Lipase from Thermomyces lanuginosus, 122,000 U/g), Lecitase Ultra (Lipase from Fusarium oxysporum, 150 U/g), Resinase A 2X (Lipase from Aspergillus oryzae, 119,600 U/g), Palatase 20,000 L (Lipase from Aspergillus oryzae, $\geq 20,000 \mathrm{U} / \mathrm{g}$ ), Lipozyme CALB (Lipase from Candida antarctica B., $5000 \mathrm{U} / \mathrm{g}$ ), Lipozyme TL 100L (Lipase from Thermomyces lanuginosus, 100,000 U/g) and Lipex $100 \mathrm{~L}$ (Lipase from Thermomyces lanuginosus, 10,000 U/g). The selection of the most suitable biocatalyst (lipase) for the in situ transesterification was done by the below steps.

Rapeseed with known oil content was ground (up to the average a particle size of $0.315 \mathrm{~mm}$ ) and weighed to achieve the required oil content. Ground rapeseeds were blended with diesel as an extraction solvent in a 1:9 $(w / w)$ oil to diesel ratio. The methanol to rapeseed oil molar ratio was 5:1. The amount of lipase was 7\% based on the amount of oil. The reaction was carried out in a conical flask which was connected to a condenser. Initial reaction temperature to select the most appropriate lipase of $40^{\circ} \mathrm{C}$ and a reaction time of $5 \mathrm{~h}$ were chosen. Diesel and grounded rapeseed blends were placed on magnetic stirrer-heaters. The mixtures were stirred continuously at a rotation speed of $250 \mathrm{~min}^{-1}$. The reaction time was started to count after the required temperature of mixture was reached and the lipase and methanol were added. The effectiveness of some lipases is increased by the water present in the reaction medium. Considering that during the reaction the water demand is compensated, the vacuum was not used in the reaction.

After $5 \mathrm{~h}$, the syntheses were completed and a magnetic stirrer-heater was stopped. The mixtures were filtered and the liquid phases containing fatty acid methyl esters were washed with distilled water. Fatty acid methyl esters were analysed by thin-layer chromatography (TLC). Rapeseed oil and its methyl esters in diethyl ether were the reference samples. Petroleum ether, diethyl ether and acetic acid was consisted as the mobile phase in an appropriate volume ratio of 80:20:1. Modified sample preparation method for thin-layer chromatography was previously reported [14]. The spots of all tested samples were compared with the spots of reference samples. The evaluation was performed by comparing the brightness, location and area of the spots. One sample with the most effective lipase was selected for further optimization of the lipase-catalysed in situ transesterification process.

\subsection{Optimization of the Lipase-Catalysed In Situ Transesterification}

After selecting the most effective lipase for the in situ transesterification process, additional experiments (according to Section 2.2) were carried out to optimize the reaction conditions to achieve the highest degree of transesterification. The transesterification experiments were performed using a reaction time of $1-9 \mathrm{~h}$, a temperature of $25-40{ }^{\circ} \mathrm{C}$, and an enzyme concentration range of 3-6\%.

The influence of the methanol to oil molar ratio on the highest degree of transesterification was not verified. In fact, only a 3:1 methanol to oil molar ratio is needed to produce biodiesel, but if a 3:1 ratio were used, then there would be a large amount of unreacted material at the end of the reaction. A twice as much methanol as needed (6:1 molar ratio of methanol to oil) is usually conventionally used by industrial biodiesel producers in this study, a slightly lower molar ratio of methanol to oil of 5:1 was chosen.

\subsection{Determination of the Rapeseed Oil Extraction Effectiveness and Methyl Ester Yield in the Reaction Product}

All samples, prepared according to Section 2.3 for the optimization of lipase-catalysed in situ transesterification reactions, were investigated, and the concentration of rapeseed oil and rapeseed oi methyl esters in reaction product. Quantitative analysis of the samples was performed using a Fourier transform infrared spectroscopy method. Analyses were made with an FTIR Spectrum RX-I spectrophotometer from PerkinElmer, according to the standard EN 14078 [35]. The total yield of oil and rapeseed oil methyl esters was calculated as presented in the methodology description of other authors [36]. According to the standard provided rapeseed oil and the total amount of rapeseed methyl ester in the reaction product was determined. 


\subsection{Determination of Transesterification Degree}

The reaction product contained the mixture of fossil diesel fuel, unreacted oil and fatty acid methyl esters was produced by transesterification process. Aiming to evaluate the effectiveness of oil transesterification, the analysis was made with a Perkin Elmer Clarus 500 gas chromatograph (detector-FID; column-Restek MXT-Biodiesel TG (15 m-0.32 mm-0.10 $\mu \mathrm{m})$ ), according to the standard EN 14105 [37]. Oil transesterification degree was calculated from amount of mono-, di- and triglycerides and initial amount of oil in rapeseed used for experiments. The method reported in our previous publications was applied [38]. The fraction of biological origin (fatty acid methyl esters produced by transesterification) in the mixture with fossil diesel should meet the requirements for transesterification degree (no less than $96.5 \%(w / w)$ ) and for glyceride (monoglycerides, diglycerides and triglycerides) content in biodiesel, therefore the transesterification degree only for biological fraction of obtained product was determined and compared for optimisation of in situ process. Each sample was analysed for three times.

\section{Results and Discussion}

\subsection{Seed Quality Analysis}

Typically, rapeseed oil can account for up to $50 \%$ of the dry weight of the seed [39]. In this study, a rapeseed oil content of $46 \pm 2 \%$ was determined. The fatty acid composition (wt\%) (C14:1-0.04 $\pm 0.01 ; \mathrm{C} 15: 0-0.33 \pm 0.06 ; \mathrm{C} 16: 0-3.73 \pm 0.12 ; \mathrm{C} 16: 1-0.20 \pm 0.01 ; \mathrm{C} 18: 0-1.80 \pm 0.21 ; \mathrm{C} 18: 1-64.84 \pm 1.03$; $\mathrm{C} 18: 2-18.47 \pm 0.94 ; \mathrm{C} 18: 3-7.42 \pm 0.66 ; \mathrm{C} 20: 0-0.61 \pm 0.05 ; \mathrm{C} 20: 1-1.33 \pm 0.02 ; \mathrm{C} 22: 0-0.43 \pm 0.06 ; \mathrm{C} 22: 1-0.45$ $\pm 0.02 ; \mathrm{C} 24: 0-0.19 \pm 0.02 ; \mathrm{C} 24: 1-0.16 \pm 0.01)$ of rapeseed oil was determined by gas chromatography. Analysis has been done in triplicates.

There are mainly unsaturated fatty acids in waste rapeseed oil: oleic acid, linoleic acid, and linolenic acid. Previous studies have reported the fatty acid composition of rapeseed oil to be as follows: Oleic acid 53.95-63.3\%; linoleic acid 20.56-21.19\% and linolenic acid 8.74-9.56\% [40,41]. In this study, as compared with other scientific results, very similar oleic $(64.84 \%)$, linoleic $(18.47 \%)$ and linolenic $(7.42 \%)$ acids contents were obtained. The fatty acid composition of rapeseed oil is completely suitable for use as a feedstock to produce biodiesel.

In this research, a $2.63 \mathrm{mg} \mathrm{KOH} \mathrm{g}^{-1}$ acid value of the extracted rapeseed oil was determined. Other researchers have determined different acid values of rapeseed oil (from 0.89 to $12.25 \mathrm{mg} \mathrm{KOH}$ $\mathrm{g}^{-1}$ ) [42]. Such oils were used for methanolysis process (methanol to oil molar ratio, 6:1) with a potassium hydroxide catalyst. Prior researchers concluded that the use of oils with a high acid number for base-catalysed biodiesel production is economically unprofitable because of the higher amount of catalyst request, longer separation time and lower methyl ester yield [42]. However, the high acidity of rapeseed oil is suitable for the lipase-catalysed in situ transesterification reaction to obtain a high fatty acid methyl ester yield, as well as for esterification of free fatty acids. In our studies lipases have not been investigated for the efficiency of the esterification process. However, it is known that lipases are able to catalyse not only transesterification reactions but also a variety of other chemical reactions such as esterification, hydrolysis or alcoholysis and they are widely used in industry [43]. Scientists have investigated the lipase (produced by Thermomyces lanuginosus) catalysed esterification of oleic acid with methanol and concluded that is a promising process for biodiesel production [44].

After analysing the seed moisture content, it was found that the moisture content in rapeseed is $4.4 \%$.

\subsection{Selection of Lipase}

The lipase-catalysed in situ transesterification process from rapeseed oil to produce biodiesel fuel was analysed. Firstly, the most effective lipase for simultaneously extracting the oil from rapeseeds using diesel fuel as an extraction solvent and the transesterification of oil with methanol was selected. Blends, prepared with eleven different lipases, were analysed by thin-layer chromatography method Figure 1. TLC glass plates with results were obtained and evaluated. 


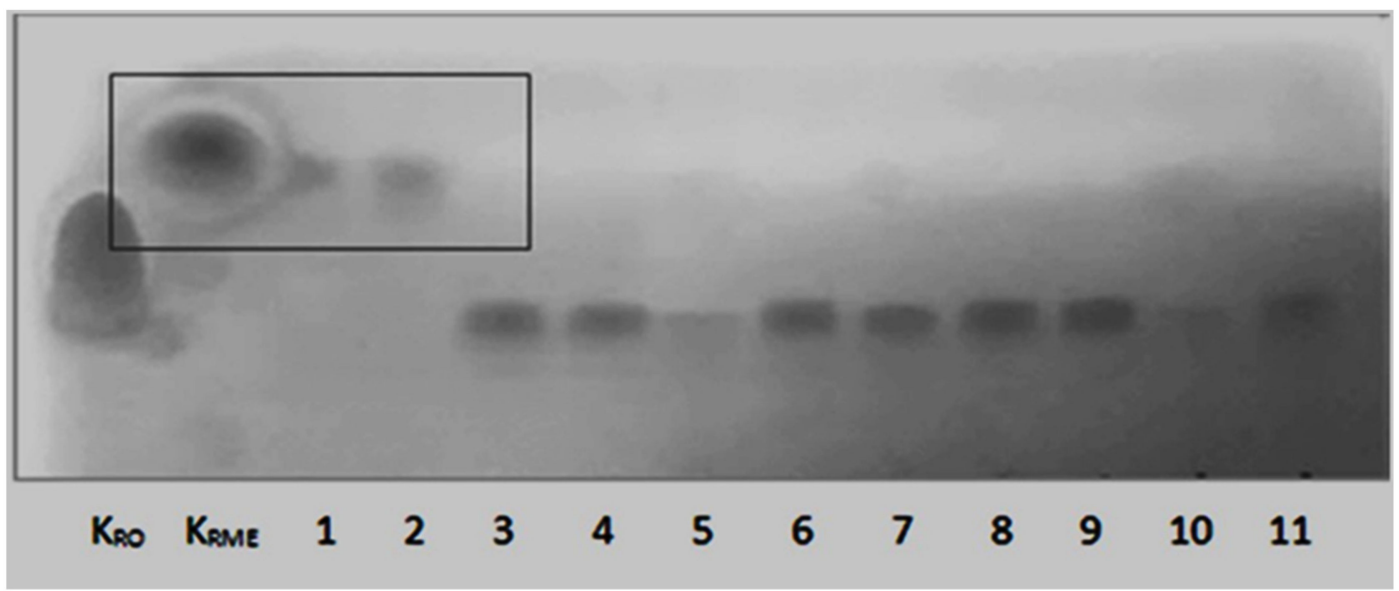

Figure 1. The efficiency of lipases in the lipase-catalysed in situ transesterification process of waste rapeseed oil. RO-rapeseed oil, RME-rapeseed methyl esters, 1-Lipozyme RM IM, 2-Lipozyme TL IM, 3-Novozyme 435, 4-Lipozyme 435, 5-Lipolase 100 L, 6-Lecitase Ultra, 7-Resinase A 2X, 8-Palatase 20,000 L, 9-Lipozyme CALB, 10-Lipozyme TL 100 L, 11-Lipex 100 L.

The results presented in the chromatogram showed that two lipases-Lipozyme RM IM and Lipozyme TL IM, are effective to use for simultaneous oil extraction and in situ transesterification process. Application of other nine lipases for biodiesel synthesis in situ was not effective. The next step was to evaluate the proportion of unreacted oil in the two effective lipases to select the more efficient one. Comparing the efficiency of these two lipases, it was found that the more effective lipase for the in situ transesterification process was Lipozyme TL IM. Other scientists have also found that Lipozyme TL IM is suitable for use for a lipase-catalysed transesterification process to produce biodiesel from sea mango oil as raw material [22]. Additionally, enzymatic syntheses of biodiesel via alcoholysis of sunflower, borage, olive and soybean oils were investigated, and it was determined that alcoholysis is more efficient with methanol than with ethanol and that the lipase Lipozyme TL IM have better effectiveness as biocatalyst than Novozyme 435 [45]. It could be stated that results of our research confirms the results obtained by other researchers [46], therefore, we selected the lipase Lipozyme TL IM as most appropriate biocatalyst for further studies.

\subsection{Optimization of the Lipase-Catalysed In Situ Transesterification Process Parameters}

Three variables-the temperature and the duration of reaction and the concentration of the selected lipase-are very important because they can effect fatty acid methyl ester (biodiesel) yield. Additionally, optimum values of these variables in turn is highly dependent on what raw material and what source of lipase are used to produce the biodiesel. Consequently, the effects of these variables on biodiesel yield when the rapeseed contained the oil of high acidity was used for transesterification in situ and the lipase Lipozyme TL IM was used as biocatalyst were studied. The same samples that were prepared for optimisation of reaction time and temperature were used to analyse the effectiveness of oil extraction and transesterification. Samples were investigated to determine the yield of rapeseed oil (RO) and rapeseed methyl esters (RME) in the biological fraction of reaction product obtained at the end of the in situ transesterification process. Experimental results are presented in Figure 2.

As shown in Figure 2, when the reaction time was $1 \mathrm{~h}$ and the reaction temperature was $25^{\circ} \mathrm{C}$, $30{ }^{\circ} \mathrm{C}$ or $40{ }^{\circ} \mathrm{C}$, the yield of rapeseed oil and rapeseed methyl ester extracted from the rapeseeds was $66.51 \%(w / w), 82.84 \%(w / w)$ and $82.63 \%(w / w)$, respectively. When the reaction time was increased to $3 \mathrm{~h}$ and the reaction temperature was $25^{\circ} \mathrm{C}$ or $30^{\circ} \mathrm{C}$, the yield of rapeseed oil and rapeseed methyl ester was $82.95 \%(w / w)$ and $87.52 \%(w / w)$, respectively; at $40{ }^{\circ} \mathrm{C}$, the yield increased to $98.54 \%(w / w)$. At the reaction times of 5, 7 or $9 \mathrm{~h}$, the yield of rapeseed oil and rapeseed methyl ester in the biological fraction of reaction product was very similar at all the chosen reaction temperatures and reached over $99 \%$. This indicates that the extraction efficiency does not depend on the reaction temperature when 
the duration of the reaction is not shorter than $5 \mathrm{~h}$ to obtain a high yield of rapeseed oil and rapeseed methyl ester in the biological fraction of reaction product. The results show that diesel is a suitable rapeseed oil extraction agent for use in the in situ transesterification process with lipase Lipozyme TL IM and methanol. In summary, using an in situ transesterification process at a reaction temperature of $25^{\circ} \mathrm{C}$ and a reaction time of $5 \mathrm{~h}$, a maximum yield $(99.95 \%(w / w))$ of rapeseed oil and rapeseed methyl ester can be obtained. The typical reaction time for the lipase-catalysed transesterification of different oil-containing raw materials obtained by other researchers ranged from $4 \mathrm{~h}$ to $72 \mathrm{~h}$ [47].

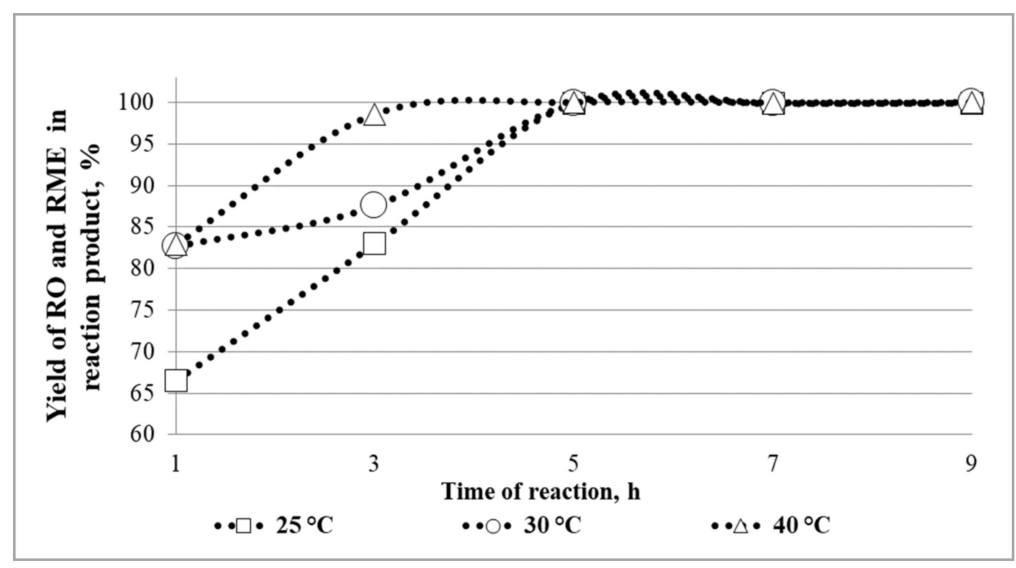

Figure 2. Yield of rapeseed oil (RO) and rapeseed methyl ester (RME) in the biological fraction of reaction product when the diesel and rapeseed oil blend ratio is 9:1 (w/w), the methanol to oil molar ratio is $5: 1$, and the lipase concentration is $7 \%$.

The addiction of the degree of transesterification and glyceride content in biodiesel on the reaction time and temperature at a molar ratio of methanol to oil of 5:1 and a lipase concentration of $7 \%$ was investigated. Temperature is an important factor to optimise for an in situ transesterification process, but in this case, it does not have a significant effect. Other sources mention that the temperature of the reaction and the acidity of the oil are two of the most important factors that generally affect the lipase-catalysed transesterification, as in most homogeneous and heterogeneous reactions [48]. A lower reaction temperature and a shorter reaction time require a lower energy input to produce biodiesel, which makes this process more environmentally beneficial and cost-effective. It is important to add that a higher reaction temperature can accelerate the transesterification process, but excessive reaction temperatures can cause denaturation of the enzyme [49]. The choice of an optimal temperature for a lipase-catalysed transesterification reaction depends on lipase and on the alcohol used. For the majority of lipase-catalysed transesterification reactions, the optimum temperature drops from $50{ }^{\circ} \mathrm{C}$ to $30{ }^{\circ} \mathrm{C}[50]$.

For this study, the reaction temperatures of $25^{\circ} \mathrm{C}$ (Figure 3a), $30^{\circ} \mathrm{C}$ (Figure $3 \mathrm{~b}$ ) and $40{ }^{\circ} \mathrm{C}$ (Figure 3c) were selected, and the effectiveness of transesterification was investigated. To investigate the influence of the reaction time, reaction duration of 1,3,5, 7 and $9 \mathrm{~h}$ were chosen. The influence of reaction time and temperature on the degree of transesterification and glyceride content in reaction product are demonstrated in Figure $3 \mathrm{a}-\mathrm{c}$ and Table 1.

The degree of transesterification, which should be no less than $96.5 \%(w / w)$ for biodiesel, complies with the requirements at the lowest time and temperature conditions: $3 \mathrm{~h}$ of reaction time at $40{ }^{\circ} \mathrm{C}$ (Figure 3c) reaction temperature gives a transesterification degree $97.63 \%(w / w)$. The lowest degree of transesterification of $46.03 \%(w / w)$ was obtained at $1 \mathrm{~h}$ of reaction time at $25{ }^{\circ} \mathrm{C}$ (Figure 3a) reaction temperature. The highest degree of transesterification of $99.89 \%(w / w)$ was obtained at $9 \mathrm{~h}$ of reaction time at $40^{\circ} \mathrm{C}$ reaction temperature However, according to the selected time and temperature conditions, not all samples obtained met the requirements for glyceride content in biodiesel fuel, as shown in Table 1. 


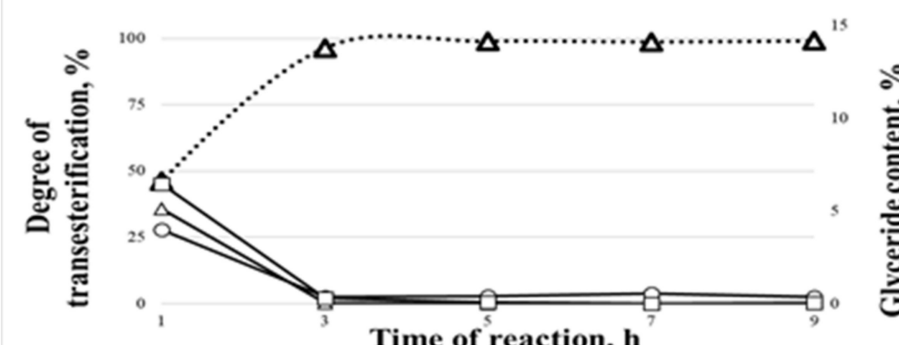

$\cdot \Delta \cdot$ Degree of transesterification $\quad-\Delta-$ Triglycerides $\sim$ - Monoglycerides

$\mathbf{a}$

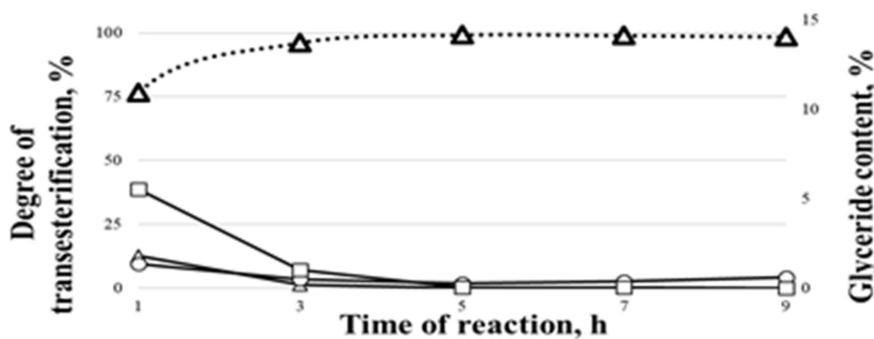

$\because \Delta \cdot$ Degree of transesterification $\quad-\Delta-$ Triglycerides $\rightarrow-$ Monoglycerides $\square-D i g y c e r i d e s$

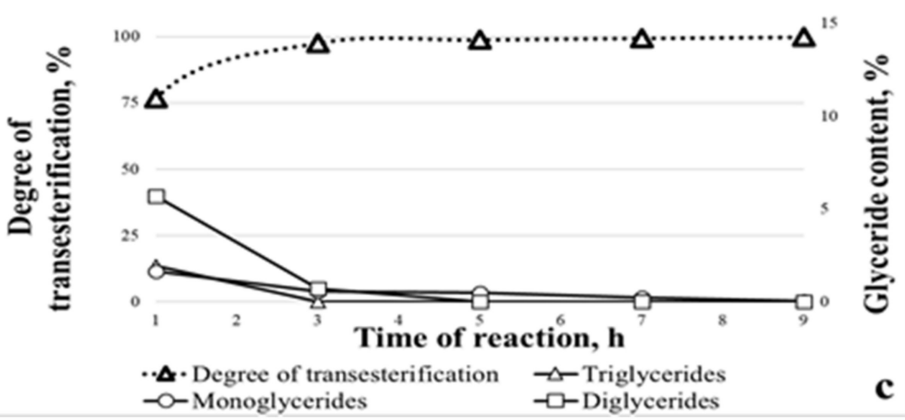

Figure 3. The temperature of the reaction: (a) $25{ }^{\circ} \mathrm{C}$, (b) $30{ }^{\circ} \mathrm{C}$ and (c) $40{ }^{\circ} \mathrm{C}$. The degree of transesterification (vertical (value) axis) and the glyceride content (secondary vertical (value) axis) dependence on the reaction time and temperature when the oil-to-methanol molar ratio is 1:5 and the lipase (Lipozyme LT IM) concentration is 7\%.

Table 1. Dependence of glyceride content in biodiesel fuel on the reaction time and temperature.

\begin{tabular}{ccccc}
\hline \multirow{2}{*}{$\begin{array}{c}\text { Reaction } \\
\text { Duration [h] }\end{array}$} & $\begin{array}{c}\text { Reaction } \\
\text { Temperature }\left[{ }^{\circ} \mathbf{C}\right]\end{array}$ & \multicolumn{3}{c}{ Glyceride Contents in Biodiesel Fuel $[\%(w / w)]$} \\
\cline { 3 - 5 } & & Monoglycerides & Diglycerides & Triglycerides \\
\hline 1 & 25 & $3.97 \pm 0.06$ & $6.43 \pm 0.07$ & $35.78 \pm 0.10$ \\
1 & 30 & $1.35 \pm 0.03$ & $5.55 \pm 0.05$ & $12.54 \pm 0.09$ \\
1 & 40 & $1.64 \pm 0.03$ & $5.70 \pm 0.04$ & $13.46 \pm 0.09$ \\
3 & 25 & $0.35 \pm 0.01$ & $0.27 \pm 0.02$ & $0.33 \pm 0.04$ \\
3 & 30 & $0.47 \pm 0.02$ & $1.01 \pm 0.03$ & $1.23 \pm 0.03$ \\
3 & 40 & $0.57 \pm 0.02$ & $0.69 \pm 0.02$ & $0 \pm 0$ \\
5 & 25 & $0.38 \pm 0.03$ & $0.06 \pm 0.02$ & $0 \pm 0$ \\
5 & 30 & $0.27 \pm 0.02$ & $0.04 \pm 0.02$ & $0 \pm 0$ \\
5 & 40 & $0.47 \pm 0.02$ & $0.01 \pm 0.01$ & $0 \pm 0$ \\
7 & 25 & $0.52 \pm 0.03$ & $0.01 \pm 0.01$ & $0 \pm 0$ \\
7 & 30 & $0.38 \pm 0.02$ & $0.02 \pm 0.01$ & $0 \pm 0$ \\
7 & 40 & $0.23 \pm 0.03$ & $0.01 \pm 0.00$ & $0 \pm 0$ \\
9 & 25 & $0.34 \pm 0.02$ & $0.02 \pm 0.01$ & $0 \pm 0$ \\
9 & 30 & $0.59 \pm 0.02$ & $0.01 \pm 0.00$ & $0 \pm 0$ \\
9 & 40 & $0.04 \pm 0.01$ & $0.01 \pm 0.00$ & $0 \pm 0$ \\
\hline
\end{tabular}

The acohol to oil molar ratio-5:1. 
The concentration of lipase (Lipozyme TL IM) $7 \%$. The glyceride content in biodiesel must not exceed $0.8 \%$ monoglycerides, $0.2 \%$ diglycerides and $0.2 \%$ triglycerides. With a reaction time of one hour and even with increasing the reaction temperature from $25^{\circ} \mathrm{C}$ to $40{ }^{\circ} \mathrm{C}$, neither the degree of transesterification nor the requirement for glyceride content in biodiesel fuel were achieved. When the reaction time was $3 \mathrm{~h}$ and the reaction temperatures were $25^{\circ} \mathrm{C}$ or $30^{\circ} \mathrm{C}$, the glyceride contents in biodiesel met the monoglyceride concentration requirements ( $0.35 \%$ and $0.47 \%$, respectively), but the diglyceride and triglyceride concentrations were too high and did not meet the requirements. Even when the degree of transesterification is sufficiently high, at $3 \mathrm{~h}$ of reaction time and $40{ }^{\circ} \mathrm{C}$ (Figure 3c) reaction temperature, the concentration of diglycerides was too high $(0.69 \%)$ and did not meet the requirements $(0.2 \%)$. The best glyceride content results in biodiesel were achieved when the reaction time was 5,7 or $9 \mathrm{~h}$ at all selected reaction temperatures. The results obtained in these conditions show a good degree of transesterification and good glyceride content in biodiesel. Therefore, it can be concluded that, to optimal duration of in situ transesterification process is $5 \mathrm{~h}$ and optimal reaction temperature is $25^{\circ} \mathrm{C}$ (Figure 3a). Other scientists have determined that it is possible to extract $99.92 \%(w / w)$ of oil from rapeseed by using diesel as solvent and to obtain $99.89 \%$ $(w / w)$ transesterification degree with using ethanol and Lipozyme TL IM as a catalyst. The optimal reaction conditions were determined as follows: A reaction time of $7 \mathrm{~h}$, a reaction temperature of $30^{\circ} \mathrm{C}$ and a catalyst concentration of 5\% (based on oil weight) [36]. At this temperature were optimised to $25^{\circ} \mathrm{C}$ and reaction time were optimised of $5 \mathrm{~h}$. In another research, was analysed the process of in situ transesterification of wet microalgae Ankistrodesmus sp. oil and optimum determined process conditions were as follows: a reaction temperature of $42^{\circ} \mathrm{C}$, molar ratio of ethanol to oil-8:1, a catalyst Lipozyme TL IM concentration of $9.6 \%$ (based on oil weight) and a reaction time of $12 \mathrm{~h}$. By using dry microalgae under these conditions resulted in $97.69 \%(w / w)$ transesterification yield [28]. In these experiments were applied the same biocatalyst as at our research and diesel as extraction solvent, but different raw material (algae) and alcohol (ethanol) were used. However, it can be assumed that by choosing methanol (rather than ethanol) it is possible to achieve a high degree of transesterification at a lower temperature and a shorter reaction time, which is of great benefit from an environmental and energy point of view.

After the optimal reaction time and temperature were determined, the next step was to select an optimal lipase concentration. To investigate the effect of the dosage of lipase on the yield of rapeseed oil and rapeseed methyl ester in the biological fraction of reaction product, the degree of transesterification and glyceride content, the concentration of lipase Lipozyme TL IM was varied from 3\% to $6 \%$ based on the amount of oil. The amount of methanol to oil molar ratio was 5:1 and the previously optimized reaction conditions were maintained. Reaction product were investigated to determine the yield of rapeseed oil and rapeseed methyl ester in the biological fraction of reaction product obtained at the end of the in situ transesterification process. Experimental results are presented in Table 2.

Table 2. Dependence of rapeseed oil (RO) and rapeseed methyl ester (RME) yield and degree of transesterification of on lipase Lipozyme TL IM concentration.

\begin{tabular}{ccc}
\hline Lipase Concentration [\%] & $\begin{array}{c}\text { Rapeseed Oil and Rapeseed Methyl Ester Yield in } \\
\text { Biological Fraction of Reaction Product }[\%(w / w)]\end{array}$ & $\begin{array}{c}\text { Degree of Transesterification } \\
{[\%(w / w)]}\end{array}$ \\
\hline 3 & $98.99 \pm 0.08$ & $93.06 \pm 0.10$ \\
4 & $99.55 \pm 0.10$ & $94.84 \pm 0.14$ \\
5 & $99.90 \pm 0.09$ & $98.75 \pm 0.08$ \\
6 & $99.95 \pm 0.05$ & $98.76 \pm 0.06$ \\
\hline
\end{tabular}

The diesel and rapeseed oil blend ratio is $9: 1(w / w)$, the methanol to oil molar ratio is $5: 1$, the reaction time is $5 \mathrm{~h}$, and the reaction temperature is $25^{\circ} \mathrm{C}$.

As shown in Table 2, when the lipase concentration was 3\%, the yield of rapeseed oil and rapeseed methyl ester in biological fraction of reaction product was $98.99 \%(w / w)$. When the lipase concentration 
was $4 \%$ or $5 \%$, the yields of rapeseed oil and rapeseed methyl ester was $99.55 \%(w / w)$ and $99.90 \%$ $(w / w)$, respectively. When the lipase concentration in reaction media was $6 \%$, the yield of rapeseed oil and rapeseed methyl increased to $99.95 \%(w / w)$. These results indicate that the extraction intensity is not dependent upon the lipase concentration in the reaction media. As seen in Table 2, for the samples with $3 \%$ and $4 \%$ lipase, the degrees of transesterification $(93.06 \%(w / w)$ and $94.84 \%(w / w)$, respectively) did not reach the requirement for biodiesel fuel (no less than $96.5 \%$ ). However, for the samples with lipase concentrations of $5 \%$ and $6 \%$, a high degree of transesterification $(98.76 \%(w / w)$ and $98.75 \%(w / w)$, respectively) was observed, and these samples met the requirements of standard perfectly. The effect of lipase concentration on glyceride content in biodiesel fuel was investigated, and the results are shown in Table 3.

Table 3. Dependence of glyceride content in biodiesel fuel on concentration of lipase Lipozyme TL IM.

\begin{tabular}{cccc}
\hline \multirow{2}{*}{$\begin{array}{c}\text { Lipase Concentration } \\
\text { [\%] }\end{array}$} & \multicolumn{3}{c}{ Glycerides Contents in Biodiesel Fuel [\%] } \\
\cline { 2 - 4 } & Monoglycerides & Diglycerides & Triglycerides \\
\hline 3 & $0.77 \pm 0.06$ & $1.58 \pm 0.05$ & $2.89 \pm 0.06$ \\
4 & $0.79 \pm 0.04$ & $1.02 \pm 0.03$ & $1.83 \pm 0.05$ \\
5 & $0.46 \pm 0.02$ & $0.07 \pm 0.01$ & $0 \pm 0.0$ \\
6 & $0.47 \pm 0.04$ & $0.06 \pm 0.02$ & $0 \pm 0$ \\
\hline methanol to oil molar ratio is 5:1, the reaction time is $5 \mathrm{~h}$, and the reaction temperature is $25^{\circ} \mathrm{C}$
\end{tabular}

Results presented in the Table 3 demonstrate, that requirements for glyceride content in biodiesel fuel are achieved with a lipase concentration of $5 \%$ or $6 \%$. When the lipase concentration in the reaction media is $3 \%$ or $4 \%$, the glyceride concentration of the biological fraction of reaction product do not meet the requirements for glyceride content in biodiesel fuel. Taking this into account, it can be concluded that a $5 \%$ lipase concentration is the most appropriate for the lipase-catalysed in situ transesterification process because of a high yield of rapeseed oil and rapeseed methyl ester $(99.90 \%(w / w))$, a high degree of transesterification $(98.76 \%(w / w))$, and optimal glyceride content in biodiesel fuel. Other scientist also was determined the optimal Lipase concentration up to $5 \%$, with using same raw material, same lipase but different alcohol-ethanol [50]. In another scientific study, researchers reported results obtained by using Ankistrodesmus sp. oil and ethanol for in situ transesterification process, with diesel as an extraction solvent and catalyst Lipozyme TL IM. They found out that optimal concentration of lipase is up to $9.6 \%$ (based on oil weight) to obtain high degree of transestericifation [28]. It can be argued that the concentration of lipase is not strongly dependent on the alcohol selected for the reaction; however, it depends in part on the type of oil used for simultaneous oil extraction and transesterification.

\section{Conclusions}

1. A diesel-biodiesel blend can be produced directly from prospective non-edible renewable raw material-rapeseed containing the oil of high acidity, by the application of simultaneous oil extraction and transesterification in situ with methanol and diesel mixture and catalysed by the lipase Lipozyme TL IM.

2. The optimal conditions for in situ transesterification process when the methanol to oil molar ratio is $5: 1$ are as follows: temperature of the reaction of $25^{\circ} \mathrm{C}$, time of the reaction of $5 \mathrm{~h}$, and lipase concentration of $5 \%$.

3. Under optimal conditions $99.90 \%(w / w)$ of oil is extracted from the seed and transesterified. The degree of transesterification of $98.76 \%(w / w)$ is obtained.

4. These results indicate that waste rapeseeds are a suitable raw material to produce biodiesel with an in situ transesterification process using the lipase Lipozyme TL IM as the catalyst and methanol as acyl receptor. The resulting biodiesel fulfils the requirements for the degree of transesterification and the requirements for glyceride content in biodiesel fuel. 
Author Contributions: Conceptualization, E.S.; methodology, E.S. and V.M.; formal analysis, formal analysis; investigation M.S., E.S. and V.M.; resources E.S.; data curation, E.S. and M.S.; writing-original draft preparation M.S., E.S. and V.M.; writing-review and editing, E.S., M.S. and V.M.; visualization, M.S.; supervision, E.S. All authors have read and agreed to the published version of the manuscript.

Funding: This research received no external funding.

Acknowledgments: Authors are thankful for biocatalyst (Lipozyme TL IM, Novozyme 435, Lipozyme 435, Lipolase 100L, Lecitase Ultra, Resinase A 2X, Palatase 20000L, Lipozyme CALB, Lipozyme TL 100L, Lipex 100L) JSC „Biopolis“ (Lithuania).

Conflicts of Interest: The authors declare no conflict of interest.

\section{References}

1. Go, A.W.; Sutanto, S.; Ong, L.K.; Tran-Nguyen, P.L.; Ismadji, S.; Ju, Y.H. Developments in in-situ (trans) esterification for biodiesel production: A critical review. Renew. Sustain. Energy Rev. 2016, 60, 284-305. [CrossRef]

2. Atabani, A.E.; Silitonga, A.S.; Badruddin, I.A.; Mahlia, T.M.I.; Masjuki, H.H.; Mekhilef, S. A comprehensive review on biodiesel as an alternative energy resource and its characteristics. Renew. Sustain. Energy Rev. 2012, 16, 2070-2093. [CrossRef]

3. Go, A.W.; Sutanto, S.; Liu, Y.T.; Tran-Nguyen, P.L.; Ismadji, S.; Ju, Y.H. In situ transesterification of Jatropha curcas L. seeds in subcritical solvent system. J. Taiwan Inst. Chem. 2014, 45, 1516-1522. [CrossRef]

4. Patel, R.L.; Sankhavara, C.D. Biodiesel production from Karanja oil and its use in diesel engine a review. Renew. Sustain. Energy Rev. 2017, 71, 464-474. [CrossRef]

5. Dasari, S.R.; Borugadda, V.B.; Goud, V.V. Reactive extraction of castor seeds and storage stability characteristics of produced biodiesel. Process. Saf. Environ. Prot. 2016, 100, 252-263. [CrossRef]

6. Koutsouki, A.A.; Tegou, E.; Kontakos, S.; Kontominas, M.G.; Pomonis, P.J.; Manos, G. In situ transesterification of Cynara cardunculus L. seed oil via direct ultrasonication for the production of biodiesel. Fuel Process. Technol. 2015, 134, 122-129. [CrossRef]

7. Wu, H.; Liu, Y.; Zhang, J.; Li, G. In situ reactive extraction of cottonseeds with methyl acetate for biodiesel production using magnetic solid acid catalysts. Bioresour. Technol. 2014, 174, 182-189. [CrossRef] [PubMed]

8. Liu, Y.; Tu, Q.; Knothe, G.; Lu, M. Direct transesterification of spent coffee grounds for biodiesel production. Fuel 2017, 199, 157-161. [CrossRef]

9. Tuntiwiwattanapuna, N.; Monono, E.; Wiesenborn, D.; Tongcumpou, C. In-situ transesterification process for biodiesel production using spent coffee grounds from the instant coffee industry. Ind. Crop. Prod. 2017, 102, 23-31. [CrossRef]

10. Choi, O.K.; Song, J.S.; Cha, D.K.; Lee, J.W. Biodiesel production from wet municipal sludge: Evaluation of in situ transesterification using xylene as a cosolvent. Bioresour. Technol. 2014, 166, 51-56. [CrossRef]

11. Salam, K.A.; Velasquez-Orta, S.B.; Harvey, A.P. A sustainable integrated in situ transesterification of microalgae for biodiesel production and associated co-product-a review. Renew. Sustain. Energy Rev. 2016, 65, 1179-1198. [CrossRef]

12. Gouveia, L.; Oliveira, A.C. Microalgae as a raw material for biofuels production. J. Ind. Microbiol. Biotechnol. 2009, 36, 269-274. [CrossRef] [PubMed]

13. Mendow, G.; Querini, C.A. High performance purification process of methyl and ethyl esters produced by transesterification. Chem. Eng. J. 2013, 228, 93-101. [CrossRef]

14. Sendzikiene, E.; Makareviciene, V.; Gumbyte, M. Reactive extraction and fermental transesterification of rapeseed oil with butanol in diesel fuel media. Fuel Process. Technol. 2015, 138, 758-764. [CrossRef]

15. Musa, I.A. The effects of alcohol to oil molar ratios and the type of alcohol on biodiesel production using transesterification process. Egypt J. Pet. 2016, 25, 21-31. [CrossRef]

16. Shahid, E.M.; Jamal, Y. Production of biodiesel: A technical review. Renew. Sustain. Energy Rev. 2011, 15, 4732-4745. [CrossRef]

17. Shuit, S.H.; Lee, K.T.; Kamaruddin, A.H.; Yusup, S. Reactive extraction and in situ esterification of Jatropha curcas L. seeds for the production of biodiesel. Fuel 2010, 89, 527-530. [CrossRef]

18. Cao, H.; Zhang, Z.; Wu, X.; Miao, X. Direct Biodiesel Production from Wet Microalgae Biomass of Chlorella pyrenoidosa through In Situ Transesterification. BioMed Res. Int. 2013, 2013, 930686. [CrossRef] 
19. Atadashi, I.M.; Aroua, M.K.; Aziz, A.R.A.; Sulaiman, N.M.N. The effects of catalysts in biodiesel production: A review. J. Ind. Eng. Chem. 2013, 19, 14-26. [CrossRef]

20. Abo El-Enin, S.A.; Attia, N.K.; El-Ibiari, N.N.; El-Diwani, G.I.; El-Khatib, K.M. In-situ transesterification of rapeseed and cost indicators for biodiesel production. Renew. Sustain. Energy Rev. 2013, 18, 471-477. [CrossRef]

21. Ginting, M.S.A.; Azizan, M.T.; Yusup, S. Alkaline in situ ethanolysis of Jatropha curcas. Fuel 2012, 93, 82-85. [CrossRef]

22. Thliveros, P.; Kiran, E.U.; Web, C. Microbial biodiesel production by direct methanolysis of oleaginous biomass. Bioresour. Technol. 2014, 157, 181-187. [CrossRef] [PubMed]

23. Fukuda, H.; Kondo, A.; Noda, H. Biodiesel fuel production by transesterification of oils. J. Biosci. Bioeng. 2001, 92, 405-416. [CrossRef]

24. Jiang, Y.; Gu, H.; Zhou, L.; Cui, C.; Gao, J. Novel in situ batch reactor with a facile catalyst separation device for biodiesel production. Ind. Eng. Chem. Res. 2012, 51, 14935-14940. [CrossRef]

25. Su, E.; You, P.; Wei, D. In situ lipase-catalyzed reactive extraction of oilseeds with short-chained dialkyl carbonates for biodiesel production. Bioresour. Technol. 2009, 100, 5813-5817. [CrossRef]

26. Jiang, Y.; Li, D.; Li, Y.; Gao, J.; Zhou, L.; He, Y. In situ self-catalyzed reactive extraction of germinated oilseed with short-chained dialkyl carbonates for biodiesel production. Bioresour. Technol. 2013, 150, 50-54. [CrossRef]

27. Makareviciene, V.; Sendzikiene, E.; Gumbyte, M. Application of Simultaneous Oil Extraction and Transesterification in Biodiesel Fuel Synthesis: A Review. Energies 2020, 13, 2204. [CrossRef]

28. Makareviciene, V.; Gumbyte, M.; Sendzikiene, E. Simultaneous extraction of microalgae Ankistrodesmus sp. oil and enzymatic transesterification with ethanol in the mineral diesel medium. Food Bioprod. Process. 2019, 116, 89-97. [CrossRef]

29. Gumbytė, M.; Makareviciene, V.; Skorupskaite, V.; Sendzikiene, E.; Kondratavicius, M. Enzymatic microalgae oil transesterification with ethanol in mineral diesel fuel media. J. Renew. Sustain. Energy 2018, 10, 013105. [CrossRef]

30. International Organization for Standardization. ISO 659:2009. Oilseeds-Determination of Oil Content (Reference Method); International Organization for Standardization: Geneva, Switzerland, 2009.

31. International Organization for Standardization. EN ISO 5509:2000. Animal and Vegetable Fats and Oils_Preparation of Methyl Esters of Fatty Acids; International Organization for Standardization: Geneva, Switzerland, 2000.

32. International Organization for Standardization. EN ISO 5508:1996. Animal and Vegetable Fats and Oils-Analysis by Gas Chromatography of Methyl Esters of Fatty Acids; International Organization for Standardization: Geneva, Switzerland, 1996.

33. International Organization for Standardization. ISO 660:2020. Animal and Vegetable Fats and Oils_Determination of Acid Value and Acidity; International Organization for Standardization: Geneva, Switzerland, 2020.

34. International Organization for Standardization. ISO 665:2020. Oilseeds-Determination of Moisture and Volatile Matter Content; International Organization for Standardization: Geneva, Switzerland, 2020.

35. European Committee for Standardization. EN 14078:2014. Liquid Petroleum Products. Determination of Fatty Acid Methyl Ester (FAME) Content in Middle Distillates. Infrared Spectrometry Method; European Committee for Standardization: Brussels, Belgium, 2014.

36. Santaraite, M.; Sendzikiene, E.; Makareviciene, V.; Kazancev, K. Biodiesel Production by Lipase-Catalyzed in Situ Transesterification of Rapeseed Oil Containing a High Free Fatty Acid Content with Ethanol in Diesel Fuel Media. Energies 2020, 13, 2588. [CrossRef]

37. European Committee for Standardization. EN 14105:2011. Fat and Oil Derivatives_Fatty Acid Methyl Esters (FAME)—Determination of Free and Total Glycerol and Mono-, Di-, Triglyceride Contents; European Committee for Standardization: Brussels, Belgium, 2011.

38. Sendzikiene, E.; Sinkuniene, D.; Kazanceva, I.; Kazancev, K. Optimization of low quality rapeseed oil transesterification with butanol by applying the response surface methodology. Renew. Energy 2016, 87, 266-272. [CrossRef]

39. Abbadi, A.; Leckband, G. Rapeseed breeding for oil content, quality, and sustainability. Eur. J. Lipid Sci. Technol. 2011, 113, 1198-1206. [CrossRef] 
40. Giakoumis, E.G. Analysis of 22 vegetable oils' physico-chemical properties and fatty acid composition on a statistical basis, and correlation with the degree of unsaturation. Renew. Energy 2018, 126, 403-419. [CrossRef]

41. Beyzi, E.; Gunes, A.; Buyukkilic Beyzi, S.; Konca, Y. Changes in fatty acid and mineral composition of rapeseed (Brassica napus ssp. oleifera L.) oil with seed sizes. Ind. Crop. Prod. 2019, 129, 10-14.

42. Kwiecien, J.; Hájek, M.; Skopal, F. The effect of the acidity of rapeseed oil on its transesterification. Bioresour. Technol. 2009, 100, 5555-5559. [CrossRef] [PubMed]

43. Aamer, F.H.; Hameed, A.S.A. Industrial applications of microbial lipazes. Enzym. Microb. Technol. 2006, 39, 235-251.

44. Nguyen, H.C.; Huong, D.T.M.; Juan, H.Y.; Su, C.H.; Chien, C.C. Liquid Lipase-Catalyzed Esterification of Oleic Acid with Methanol for Biodiesel Production in the Presence of Superabsorbent Polymer: Optimization by Using Response Surface Methodology. Energies 2018, 11, 1085. [CrossRef]

45. Hernı̨ndez-Martkn, E.; Otero, C. Different enzyme requirements for the synthesis of biodiesel: Novozym-35 and Lipozyme-TL IM. Bioresour. Technol. 2008, 99, 277-286. [CrossRef]

46. Rodrigues, R.C.; Volpato, G.; Wada, K.; Ayub, M.A.Z. Enzymatic synthesis of biodiesel from transesterification reactions of vegetable oils and short chain alcohols. J. Am. Oil Chem. Soc. 2008, 85, 925-930. [CrossRef]

47. Fjerbaek, L.; Christensen, K.V.; Norddahl, B. A review of the current state of biodiesel production using enzymatic transesterification. Biotechnol. Bioeng. 2009, 102, 1298-1315. [CrossRef]

48. Stergiou, P.-Y.; Foukis, A.; Filippou, M.; Koukouritaki, M.; Parapouli, M.; Theodorou, L.G.; Papamichael, E.M. Advances in lipase-catalyzed esterification reactions. Biotechnol. Adv. 2013, 31, 1846-1859. [CrossRef] [PubMed]

49. Nie, K.; Xie, F.; Wang, F.; Tan, T. Lipase catalyzed methanolysis to produce biodiesel: Optimization of the biodiesel production. J. Mol. Catal. B Enzym. 2006, 43, 142-147. [CrossRef]

50. Antczak, M.S.; Kubiak, A.; Antczak, T.; Bielecki, S. Enzymatic biodiesel synthesis-Key factors affecting efficiency of the process. Renew. Energy 2009, 34, 1185-1194. [CrossRef]

(C) 2020 by the authors. Licensee MDPI, Basel, Switzerland. This article is an open access article distributed under the terms and conditions of the Creative Commons Attribution (CC BY) license (http://creativecommons.org/licenses/by/4.0/). 